\section{Editorial: desempenho do comitê editorial em 2017, ORCID e IMRAD}

Lucas Massimo' iD, Karolina Mattos Roeder" ii

e Paulo Franz"II id

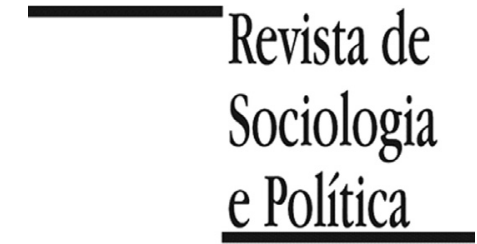

DOI 10.1590/1678-987318266600
$\mathrm{N}$ esse editorial apresentamos os dados relacionados ao processo de arbitragem dos artigos submetidos ao nosso periódico durante 2017 e parcutiremos duas novidades. a identificação das seções dos resumos e o link para o registro dos autores na plataforma ORCID, duas regras que já passaram a ser observadas nos artigos publicados a partir de 2018.

Pelo quinto ano consecutivo o editorial do fascículo de junho faz um balanço do desempenho da Revista na arbitragem dos manuscritos submetidos entre janeiro e dezembro do ano anterior. Tornar públicas tais informações tem a vantagem de fornecer aos futuros autores parâmetros objetivos relativos ao tempo de arbitragem e ao tipo de decisão tomada pelos editores. É possível também ter conhecimento sobre a abrangência territorial e sobre a área de conhecimento dos autores que escolheram nosso periódico nos últimos anos. Esperamos que, ao tornar públicos tais dados, possamos deixar mais informada a decisão para submeter artigos em nosso periódico, além de fomentar práticas alinhadas com a transparência na comunicação científica. No editorial publicado em junho de 2017 apresentamos dados acerca do quadriênio 2013-2016, e nesse editorial vamos comparar apenas os resultados observados em dois anos, 2017 e 2016.

Nos Gráficos 1 e 2 há informações sobre o perfil dos autores que submeteram seus manuscritos à Revista de Sociologia e Política. O Gráfico 1 compara a área do conhecimento, que é obtida através da vinculação do autor ao departamento ou Programa de Pós-Graduação declarado. A primeira informação que deve ser observada é a pequena elevação na população de autores. Em 2017 recebemos propostas de manuscritos assinadas por 292 autores, um número que foi ligeiramente mais elevado do que em 2016, quando 272 pesquisadores submeteram seus artigos ao nosso periódico. A maior parte dos autores que procuraram a Revista em 2017 ainda é vinculada a departamentos ou programas da área de Ciência Política, muito embora tenha ocorrido uma diminuição desse contingente em relação a 2016, uma queda que também se observa na área Relações Internacionais. O contingente que mais se expandiu em relação a 2016 foi o dos autores vinculados a outras áreas, que chegou a doze por cento em 2017.

No Gráfico 2 vemos que a maioria dos autores que submetem seus manuscritos para a Revista são brasileiros situados na região sudeste, e que esse predomínio ficou um pouco mais saliente em 2017 (devido ao aumento de 38,6 para 43,5\% na comparação com 2016). O gráfico também mostra que, comparando com o anterior, houve uma redução na participação de autores situados em outros países da América Latina, e que a submissão espontânea de autores vinculados à Europa, Estados Unidos, Ásia e Oceania se manteve fixa, na faixa $\operatorname{dos} 10 \%$.

O último dado sobre a população dos autores dos artigos submetidos ao nosso periódico refere-se ao seu gênero. A Tabela 1 apresenta a distribuição dessa informação para os autores que submeteram artigos para a Revista em 2016 e 2017. 
Gráfico 1 - Vínculo dos autores por área do conhecimento

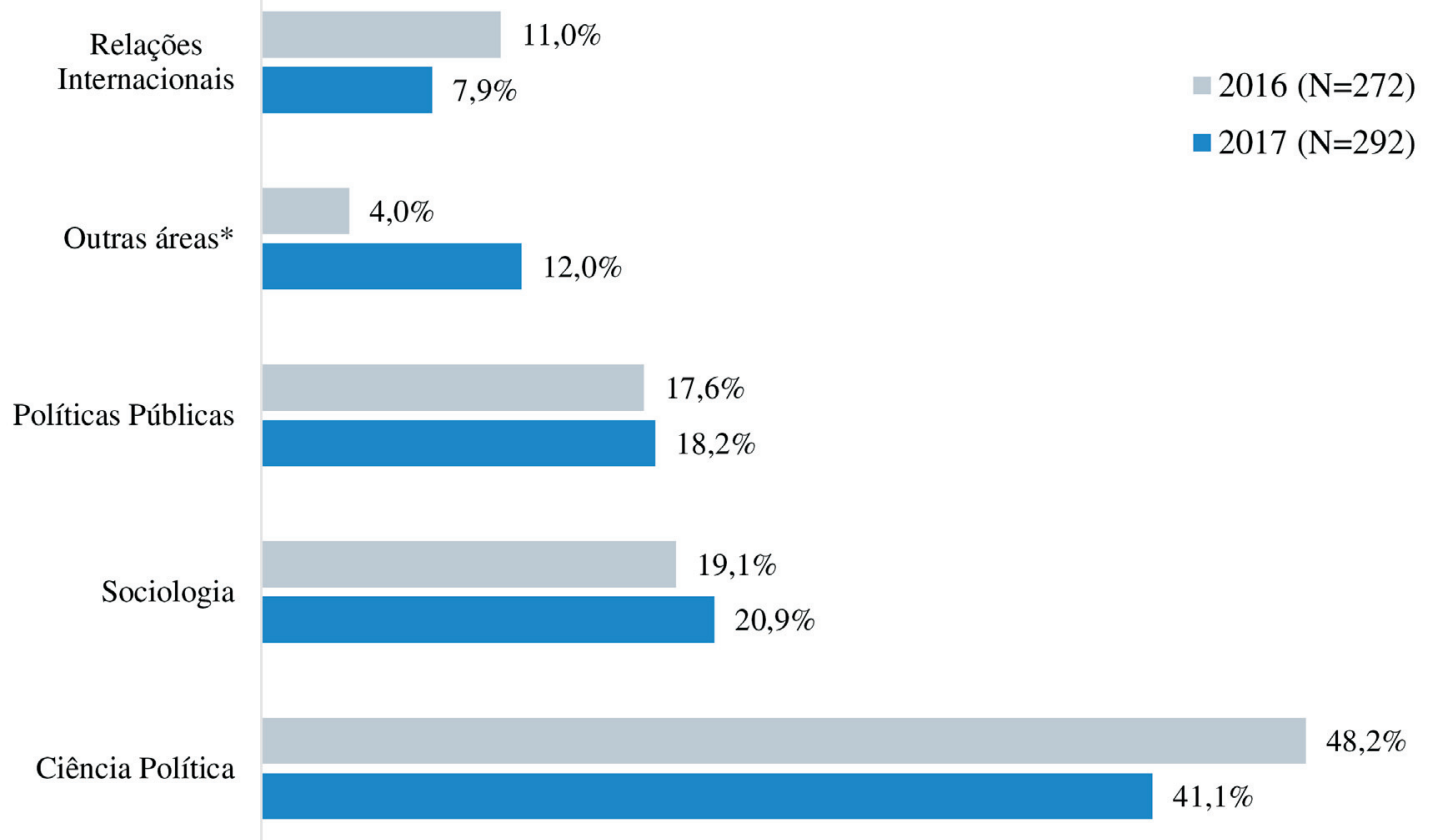

Fonte: elaboração própria, com base no arquivo da Revista de Sociologia e Política.

* Na área de Políticas Públicas agregamos autores que pertencem a programas ou departamentos de Economia, de Administração, de Gestão Pública, Políticas Públicas e Administração Pública. Na área de Sociologia agregamos o vínculo aos programas de Ciências Sociais, Ciências Humanas ou Sociologia. Em "Outras áreas" estão agregados os vínculos com Direito, Geografia, História, etc.

Tabela 1 - Distribuição dos autores por gênero

\begin{tabular}{lcc}
\hline & $\mathbf{2 0 1 6}$ & $\mathbf{2 0 1 7}$ \\
\hline Feminino & $36 \%$ & $34,9 \%$ \\
Masculino & $64 \%$ & $65,1 \%$ \\
Total & 272 & 292 \\
\hline
\end{tabular}

Fonte: elaboração própria, com base no arquivo da Revista de Sociologia e Política.

A Tabela 2 faz uma comparação dos tipos de decisões tomadas pelos editores em 2016 e 2017. Deve-se destacar a elevação de 7,4\% na quantidade de artigos submetidos espontaneamente ao periódico: em 2016 recebemos 149 manuscritos e em 2017 foram submetidas 160 propostas de artigos ou ensaios bibliográficos entre janeiro e dezembro. A taxa de manuscritos recusados em análise preliminar pelos editores se manteve na faixa dos sessenta por cento, com um aumento de $13,7 \%$ comparando os valores de 2017 com os valores de 2016. O tipo de decisão que mais aumentou nesses dois anos foi pela aprovação condicionada à revisão (a elevação é de 70\%) e o tipo de decisão que mais caiu foram as decisões pela reprovação com base em pareceres (redução de 33 pontos percentuais) e a recusa com recomendação da reapresentação (que reduziu $14,3 \%$ ). A quantidade de textos aprovados no processo de arbitragem se manteve na faixa dos dez pontos percentuais.

A Tabela 3 apresenta o tempo dispensado na tomada de cada decisão. Vemos que todos os prazos se elevaram em 2017. O tempo de espera para uma recusa preliminar quase se multiplicou por três: passamos de 32,4 dias para 82,8 dias para se tomar essa decisão, em média. $\mathrm{O}$ tempo de espera dos autores que 
Gráfico 2 - Regiões das instituições às quais os autores se declaram vinculados

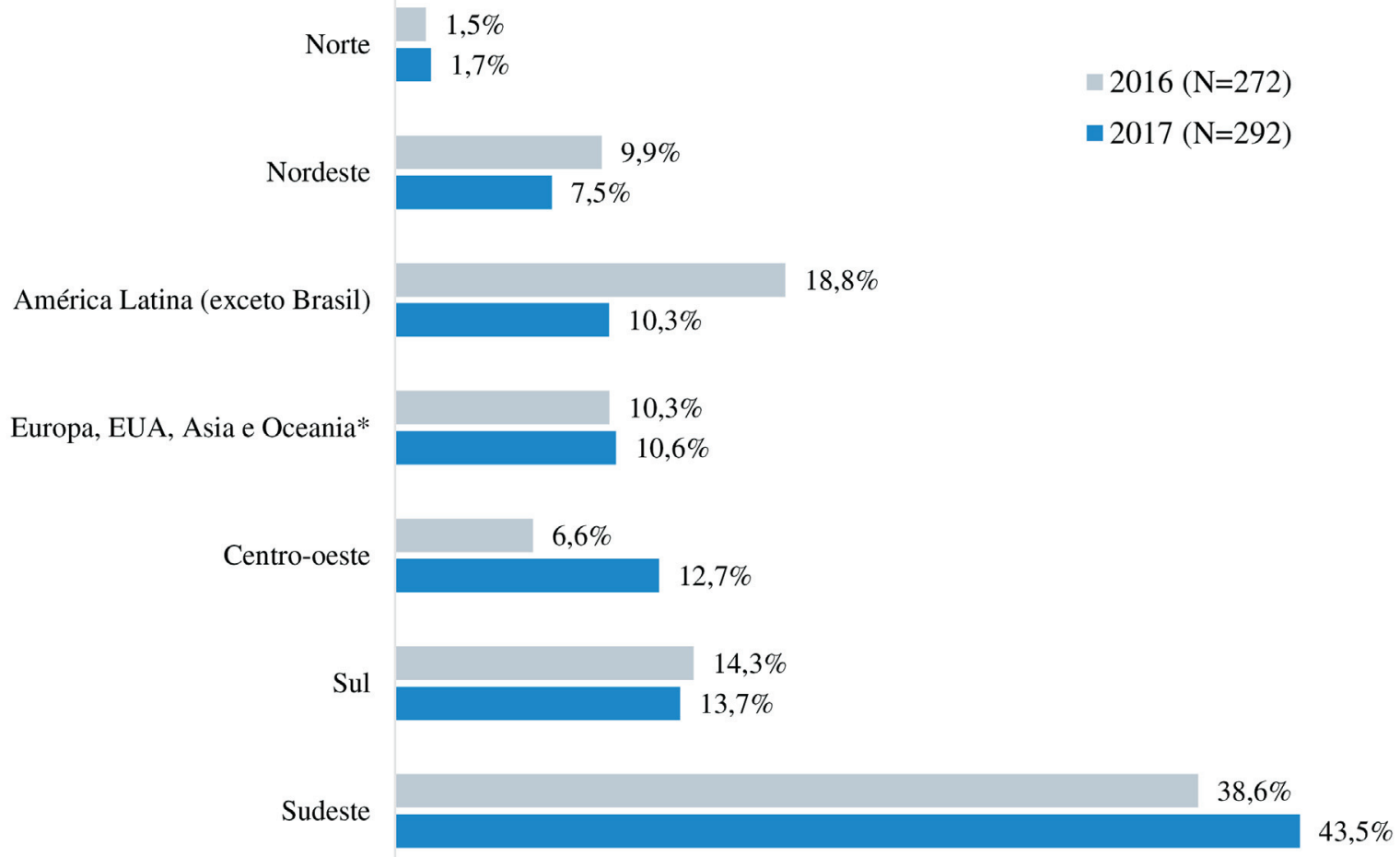

Fonte: elaboração própria, com base no arquivo da Revista de Sociologia e Política.

*A menção à Ásia deve-se a seis autores russos e a um indiano. Em 2017 recebemos uma submissão de dois autores australianos. Nos últimos editoriais não apareciam a Ásia e a Oceania pois não havia autores provenientes desses lugares.

tiveram seus textos recusados após a arbitragem anônima, por no mínimo dois pareceristas, subiu de 135 para 205 dias, e o prazo em que os artigos foram aprovados também ficou mais extenso em 2017 (em média o prazo se eleva de cerca de 140 para 180 dias). Os únicos prazos que se mantiveram estáveis foram os dados relativos ao prazo de emissão dos pareceres, que é determinado pelo conjunto dos pareceristas, sem relação direta com o trabalho realizado pelo comitê editorial.

Os resultados presentes na Tabela 3 são preocupantes. Eles revelam que em 2017 o tempo médio de espera para uma resposta ficou um pouco abaixo de três meses (para os autores que não receberam pareceres) e um pouco acima de seis meses (para os autores que receberam pareceres). Temos conhecimento de que esses prazos são longos. Ademais, é importante frisar que a dispersão no tempo de espera ficou ligeiramente inferior em 2017, visto que o coeficiente de

Tabela 2 - Decisões tomadas pelos editores nos últimos dois anos

\begin{tabular}{lccc}
\hline & $\mathbf{2 0 1 6}(\boldsymbol{\%})$ & $\mathbf{2 0 1 7}(\boldsymbol{\%})$ & Comparação com ano anterior (\%) \\
\hline Recusa preliminar & 63,8 & 67,5 & 13,7 \\
Reprovado com pareceres & 14,1 & 8,8 & $-33,3$ \\
Recusado com reapresentação & 4,7 & 3,8 & $-14,3$ \\
Aprovação condicionada à revisão & 6,7 & 10,6 & 70 \\
Aprovado & 10,7 & 9,4 & $-6,3$ \\
Total & $\mathrm{N}=149$ & $\mathrm{~N}=160$ & 7,4 \\
\hline
\end{tabular}

Fonte: elaboração própria, com base no arquivo da Revista de Sociologia e Política. 
Tabela 3 - Tempo dispensado na tomada de decisão (em dias)

\begin{tabular}{|c|c|c|c|c|c|c|}
\hline & \multicolumn{3}{|c|}{2016} & \multicolumn{3}{|c|}{2017} \\
\hline & Média & $\begin{array}{c}\text { Desvio } \\
\text { padrão }\end{array}$ & $\mathrm{CV}^{*}$ & Média & $\begin{array}{l}\text { Desvio } \\
\text { padrão }\end{array}$ & $\mathbf{C V}^{*}$ \\
\hline Recusa preliminar & 32,4 & 15,2 & $46,9 \%$ & 82,8 & 31,3 & $37, \%$ \\
\hline Reprovado com pareceres & 134,9 & 37,3 & $27,7 \%$ & 205,4 & 45,1 & $22,0 \%$ \\
\hline Aprovado & 142,3 & 50,3 & $35,4 \%$ & 187,9 & 68,6 & $36,5 \%$ \\
\hline Emissão de pareceres por avaliadores anônimos & 44,3 & 21,7 & $49,0 \%$ & 41,9 & 21,7 & $53,5 \%$ \\
\hline
\end{tabular}

Fonte: elaboração própria, com base no arquivo da Revista de Sociologia e Política.

* Coeficiente de variação.

variação diminuiu nas decisões pela recusa e se manteve praticamente inalterado na decisão pela aprovação. Isso significa que o prejuízo que estamos mensurando com esses dados afetou o conjunto dos autores de modo indistinto, pois todos os autores que apresentaram suas propostas para nosso periódico receberam as respostas em prazos mais longos do que o desejado.

A demora na resposta aos autores é um problema grave para a comunicação científica por várias razões. Em primeiro lugar, os resultados das pesquisas podem ficar defasados logo quando são publicados. Por exemplo, há um prejuízo indiscutível para os estudos realizados com base em dados de financiamento eleitoral, uma modalidade de publicação estratégica para um periódico que visa se firmar como referência no campo disciplinar da Ciência Política. Em segundo lugar, a demora impede que o autor destine o seu manuscrito rapidamente para outro periódico, no caso de recusa. Ainda, além do prejuízo ao autor, os danos decorrentes da demora na avaliação também atingem os Programas de Pós-graduação aos quais eles são vinculados, em razão da demora em fazer o trabalho desenvolvido nos grupos de pesquisa se exprimir em indicadores de produção científica.

Estamos atentos a essas dificuldades. Redesenhamos completamente o fluxo de tarefas em que ocorre a análise preliminar com o objetivo de acelerar o processo de arbitragem em desk review. A partir desse ano nosso comitê passou a utilizar algumas novidades na plataforma ScholarOne ${ }^{\circledR}$. O processo de desk review é realizado diretamente na plataforma, agilizando a comunicação interna. Essa medida visa tornar mais célere a análise da adequação dos manuscritos ao escopo editorial da Revista, que é realizada apenas pelos editores. Esperamos em 2018 tomar decisões em uma média de 45 dias (para os artigos que forem recusados em análise preliminar). Além disso, a partir deste ano os autores já podem indicar pareceristas para seus artigos, uma medida que nos ajudará a ganhar tempo durante o processo de avaliação, devido à redução do tempo necessário para a designação dos colaboradores que farão os pareceres.

Além desse breve balanço, apresentamos duas novidades que estão em andamento a partir de 2018: a identificação das seções nos resumos e a publicação dos ORCIDs dos autores.

O "ORCID iD" é um identificador digital único, internacional e intransferível, destinado a cientistas de todo o mundo. Pesquisadores escrevem, publicam, solicitam financiamento, trabalham em universidades e participam de conferências. É muito comum, nas várias organizações por quais passam, haver divergências quanto ao nome, a presença de homônimos, grafia incorreta ou ordem diferente de nomes que os autores utilizam. A ideia do ORCID iD é conferir um identificador exclusivo para cada indivíduo, evitar os erros de identificação e conectar todas as atividades acadêmicas e filiações do pesqui- 
${ }^{1}$ É possível conferir a lista de todas as organizações que aparecem como membros da rede ORCID nesse link https://orcid.org/members.
2 Acrônimo utilizado em língua inglesa para designar a justaposição de quatro informações sobre o manuscrito: Introduction, Methods, Results and Discussion.

\footnotetext{
${ }^{3}$ Como vimos na Tabela 4 do editorial publicado em junho de 2017, essa taxa caiu de $57,7 \%$ para $25,1 \%$ entre o início e o final do quadriênio (Massimo 2017).
}

sador. O registro é gratuito para membros individuais. Basta realizá-lo uma vez só e utilizá-lo sempre nas publicações científicas, no cadastro na universidade onde leciona e nas agências de fomento. Os pesquisadores podem editar e manter o seu registro, controlando a privacidade de cada item cadastrado. $\mathrm{Na}$ medida em que as instituições se tornam membros, o registro passa a ser integrado, não necessitando a inclusão manual por parte do pesquisador. Dessa forma, o ORCID facilita o compartilhamento de atividades e publicações acadêmicas bem como a comunicação científica entre os autores.

A ORCID é uma organização sem fins lucrativos, hoje conta com 28 funcionários e 842 organizações-membro no mundo todo (entre elas as universidades de Harvard, de Stanford, MIT e a NASA) que mantêm a estrutura da organização. Mais de quarenta países possuem membros organizacionais e dezessete firmaram consórcio governamental com esta organização. No Brasil, o CNPq, a CAPES e o CONFAP (Conselho Nacional das Fundações Estaduais de Amparo à Pesquisa) aparecem na lista de 'patrocinadores' associados ao ORCID. Entre as organizações listadas aparece a Rede Nacional de Ensino e Pesquisa (RNP), o Instituto Brasileiro de Informação em Ciência e Tecnologia (IBICT), além da SciELO ${ }^{1}$.

A Revista de Sociologia e Política, na intenção de colaborar com a transparência da comunicação científica e acompanhar a tendência dos periódicos internacionais, incluiu já em 2018 o ORCID no fluxo de trabalho, adotando a obrigatoriedade do registro de todos os autores que publicarem na Revista a partir deste ano.

Finalmente, adotamos uma medida que visa aperfeiçoar a comunicação científica desde os resumos. A Revista de Sociologia e Política foi um dos primeiros periódicos brasileiros a tornar obrigatório no ato da submissão o envio de um formulário para o resumo estruturado no formato IMRaD ${ }^{2}$. Esse protocolo foi iniciado ainda no primeiro semestre de 2013, quando esperávamos que os próprios autores expusessem em seus resumos respostas suficientemente claras a perguntas elementares, tais como: Do que trata e qual é o objetivo da sua pesquisa? Como se realizou a pesquisa? Como os dados foram obtidos, ou como foram processados? O que foi descoberto? Quais os principais achados do artigo? O que significam os resultados do seu artigo? O que os achados acrescentam à literatura científica sobre o tema?

Essas são perguntas básicas, e desde a introdução do formulário de resumo estruturado esse tem sido um instrumento bastante útil tanto aos editores como para os autores. Esse documento revela se um determinado artigo encontra-se ou não alinhado ao escopo do nosso periódico, quais subáreas do campo disciplinar da ciência política o manuscrito se encaixa, qual é a técnica empregada pelos autores, o que nos auxilia a encontrar pareceristas com aderência para cada proposta de artigo. O resultado aparece em taxas cada vez mais reduzidas de recusa do parecerista em realizar a avaliação do manuscrito ${ }^{3}$, além da redução na quantidade de textos recusados com base em pareceres, exibida na Tabela 2 acima.

Contudo, até o ano passado, o modelo de resumo estruturado era um tópico que ficava restrito aos editores e aos autores que submetiam artigos ao nosso periódico. Os resumos eram publicados seguindo o formato da estrutura IMRaD, mas essa estrutura passava despercebida aos leitores. Isso mudou em 2018 quando os termos 'Introdução', 'Métodos', 'Resultados' e 'Discussão' passaram a ser grafados em negrito no parágrafo do resumo. Além disso, na composição da página em HMTL, é possível inserir cada uma dessas partes como item separado dos demais. 
Com a identificação das partes dos resumos esperamos qualificar a maneira como os artigos veiculados em nosso periódico são recebidos pela comunidade científica. A disposição do resumo em seções quebra a leitura, e esse arranjo, comum em outras áreas científicas, facilita identificar as informações básicas do artigo. É uma alteração simples do ponto de vista da produção gráfica, mas que poderá incrementar a maneira como as referências bibliográficas serão assimiladas no futuro. Ademais, com essa distinção será possível mapear de modo mais eficiente as diferenças entre os artigos que integram o nosso acervo, sendo possível conduzir análises sobre a produção bibliográfica da Ciência Política de modo mais automatizado. Esperamos nos manter atentos a essas transformações no consumo e na mensuração da produção acadêmica, sem perder de vista a centralidade de alguns fundamentos da comunicação científica, como a delimitação correta de um objeto, o relato conciso das técnicas, a descrição precisa dos resultados obtidos, e a discussão substantiva sobre seus achados.

Lucas Massimo, Karolina Roeder e Paulo Franz, com a colaboração de Adriano Codato e Bruno Bolognesi

'Lucas Massimo (lucasmassimo@gmail.com) é doutor em Ciência Política pela Universidade Federal do Paraná, professor do Centro Universitário Internacional Uninter, pesquisador do Núcleo de Pesquisa em Sociologia Política Brasileira (NUSP-UFPR) e editor executivo da Revista de Sociologia e Política. Vínculo Institucional: Escola Superior de Gestão Pública, Política, Jurídica e Segurança, UNINTER, Curitiba, PR, Brasil.

IIKarolina Mattos Roeder (karolinamattosroeder@gmail.com) é doutoranda no Programa de Pós-Graduação em Ciência Política da Universidade Federal do Paraná (UFPR), pesquisadora do Núcleo de Pesquisa em Sociologia Política Brasileira (NUSP-UFPR) e editora assistente da Revista de Sociologia e Política. Vínculo Institucional: Programa de Pós-Graduação em Ciência Política, UFPR, Curitiba, PR, Brasil.

IIIPaulo Franz (pfranzj@gmail.com) é doutorando no Programa de Pós-Graduação em Ciência Política da Universidade Federal do Paraná (UFPR), pesquisador do Núcleo de Pesquisa em Sociologia Política Brasileira (NUSP-UFPR) e editor assistente da Revista de Sociologia e Política. Vínculo Institucional: Programa de Pós-Graduação em Ciência Política, UFPR, Curitiba, PR, Brasil.

\section{Referências}

Massimo, L., 2017. Editorial. Revista de Sociologia e Política, 25(62), pp.3-9. DOI: 10.1590/1678-987317256200

This is an Open Access article distributed under the terms of the Creative Commons Attribution Non-Commercial License which permits unrestricted non-commercial use, distribution, and reproduction in any medium provided the original work is properly cited. 